\title{
RESPONSABILIDADE E INFECÇÕES HoSPITALARES: a Abordagem Francesa
}

\author{
RESPONSABILITY AND HOSPITALARY INFECTIONS: \\ THE FRENCH APPROACH
}

Eric Mondielli ${ }^{\star}$

\section{RESUMO}

A partir da apresentação dos traços marcantes do novo regime jurídico francês relativo às infecções hospitalares, buscou-se precisar as implicaçōes no plano contencioso da necessária confirmação do caráter culposo pelo legislador, tendo em conta certos desenvolvimentos jurisprudenciais evocados previamente; em seguida, examinou-se o direito à reparação e a ação de responsabilidade no caso de risco hospitalar. Foram analisadas, também, as modificaçōes introduzidas pela lei de 31 de dezembro de 2002 relativa à responsabilidade civil médica em matéria de indenização das infecções hospitalares.

\section{Palavras-chave}

Infecção Hospitalar; Responsabilidade Civil; Direito Sanitário; Risco Hospitalar.

\section{ABSTRACT}

From the presentation of the most important traces of the French new legal regimen relative to the hospital infections, one searched to precise the implications in the litigious plan of the necessary confirmation of the guilty character by the legislator, having in account certain jurisprudential developments evoked previously; after that, one examined the right to the repairing and the action for damages in case of hospital risk. The modifications introdu-

(*) Maître de conférences en droit public, Faculté de droit et des sciences politiques de Nantes; Directeuradjoint du Centre d'études et de recherche en droit européen de la santé (CERDES) de Nantes. E-mail: <eric.mondielli@droit.univ-nantes.fr>. 
ced for the law of 31 of december of 2002 relative to the medical civil liability regarding indemnity of hospital infections were also analyzed.

\section{Key words}

Hospital Infection; Civil Liability; Health Law; Hospital Risk.

\section{INTRODUÇÃO}

A infecção hospitalar(1), que pode ser definida como uma infecção contraída nos estabelecimentos de saúde, constitui um problema de saúde pública real que gera um custo econômico e humano considerável. Para a Agência Nacional de Acreditação e Avaliação em Saúde (ANAES) esse tipo de infecção seria um indicador da qualidade dos serviços e dos estabelecimentos de saúde do qual depende a acreditação. Este tipo de indicador é, incontestavelmente, significativo para os gestores e administradores, mas o é, sobretudo, para os doentes que consideram que é inadmissível deixar um lugar supostamente de cura, às vezes, mais doente que quando da sua admissão. Mas, ao mesmo tempo é, também, evidente que o risco zero em medicina não existe.

Sabe-se que a luta contra as infecções contraídas nos estabelecimentos de saúde constitui um desafio permanente para o profissional da saúde. Certos estudos indicam que $10 \%$ das pessoas hospitalizadas seriam vítimas de uma infecção hospitalar quando de sua passagem em estabelecimentos de saúde e essas infecções causariam diretamente quase 10 mil mortes por ano. Outros estudos somam 800 mil os doentes atingidos desse tipo de infecção e avalia-se que ela estaria na origem de 10 mil mortes. Entre os setores mais atingidos figuram a cirurgia e a reanimação. Enfim, certos números são bastante inquietantes, dado que algumas estatísticas mostraram que um paciente tem $100 \%$ de possibilidades de contrair uma infecção hospitalar se passar um mês em reanimação(2).

Apenas recentemente o conceito de infecção hospitalar foi apreendido pelo direito francês. No plano normativo, até agora a atenção recaía sobre a organização da luta contra as infecçōes hospitalares. Os textos regulamen-

(1) Em francês: infection nosocomiale, do latim nosocomium. hospital e do grego nosos. doença, komein: cuidar.

(2) cf. L'Express, 8 março 2001, "Hôpitaux, cliniques: ce que l'on vous cache", S. O'Dy e M. Batiste; v. também o artigo de RAYSSAC, R. Le sort des infections nosocomiales. ESPER, C. Les nouvelles instances de réparation des risques sanitaires. Actualités JuriSanté, n. 34, p. 50, déc. 2001/janv. 2002; V. DUNETON, P. et al. Organisation et structures de lutte contre les infections nosocomiales en 1995. Médecine et Droit, n. 11, p. 2, 1995. 
tares, com efeito, tiveram por objeto: 1 - criar organismos de luta contra as infecções hospitalares (decreto de 6 de maio de 1988 relativo à organização da vigilância e à prevenção das infecções hospitalares nos estabelecimentos de hospitalização públicos e privados que participam no serviço público hospitalar, que instituiu os Comitês de Luta contra as Infecções Hospitalares nos estabelecimentos de saúde - $\mathrm{CLIN}^{(3)}$ - ou o decreto de 3 de agosto de 1992 que institui o Comitê Técnico Nacional das Infecções Hospitalares CTNIN(4) - e as estruturas inter-regionais de luta contra as infecções hospitalares $\left.{ }^{(5)}\right) ; 2$ - elaborar normas em matéria de assepsia e profilaxia; 3 elaborar regras e princípios deontológicos. Pode-se recordar que o art. 71 desse código de deontologia médica afirma que o médico tem a obrigação "de velar pela esterilização e a descontaminação dos dispositivos médicos que utiliza e a eliminação dos dejetos médicos de acordo com os procedimentos regulamentares" e que o art. 49 impõe ao médico que empregue todos os meios disponiveis para assegurar as regras de higiene e de profilaxia. Mais recentemente, a lei de $1^{\circ}$ de julho de 1998 relativa ao reforço da vigilância sanitária e ao controle da segurança dos produtos destinados ao homem obrigou os estabelecimentos de saúde a organizar no seu seio a luta contra as infecções hospitalares.

Por outro lado, a questão da reparação da infecção hospitalar foi, até à lei de 4 de março de $2002^{(6)}$ e mais recentemente a lei de 31 de dezembro de $2002^{(7)}$, relativa à responsabilidade civil médica, ignorada pelo legislador. Em conseqüência disso, a questão da indenização das pessoas atingidas por infecções hospitalares ficou sujeita ao regime da responsabilidade por culpa. Diversas flexibilizações ou interpretaçōes na esfera das jurisprudências civil e administrativa permitiram, contudo, desenvolver abordagens mais favoráveis aos doentes. A doutrina jurídica pôs, nestes últimos anos, larga-

(3) Com base numa dinâmica promovida pelo Conselho da Europa (V. Resolução do Comitê dos Ministros de 19 setembro 1972 convidando os États a adotar as medidas adequadas para a "Higiene hospitalar", as circulares de 18 outubro 1973" (Circulaire SP 5.543-5.468-18.10.73) e $1^{\circ}$ setembro 1975 (Circulair n. 2.805 SP 4.42-9516-1.09.75) implantaram um tipo de vigilância hospitalar com a criação em cada hospital de um CLIN. Mas, foi só depois do decreto de 1988 que todo estabelecimento hospitalar dispôs de um CLIN, que tem por missão organizar e coordenar a vigilância, a prevenção e a educação continuada em matéria de luta contra as infecçōes hospitalares. Eles são compostos por médicos, farmacêuticos, enfermeiros e diretores do estabelecimento. Note-se, também, que ele é assistido, na maioria dos estabelecimentos de saúde, por pessoas da higiene hospitalar.

(4) O CTNIN aparece como uma instância de proposição, coordenação e avaliação constituída por peritos hospitalares. O comitê propõe os objetivos prioritários e as metodologias padronizadas de vigilância e de prevenção ao Ministro.

(5) Existem cinco centros de coordenaçāo da luta contra as infecções hospitalares (CCLIN) atuando em nível inter-regional, que servem de apoio técnico para os estabelecimentos hospitalares. Eles têm por missão implementar a política definida no plano nacional e estimular a cooperação inter-hospitalar (rede de vigilância, de documentação etc.). V. CCLIN Paris-Nord (http://www.ccr.jussieu.fr/cclin/Welcom.html), CCLIN Ouest (http://www.ccliouest.com), CCLIN Sud-Est(http://www.sudest.univ-lyon1.fr/), CCLIN SudOuest (http://www.cclin-sudouest.com/).

(6) Loin. 2002-303 du 4 mars 2002, J.O. 5 mars 2002.

(7) Loi n. 2002-1577, J. 0. 31 décembre 2002. 
mente em evidência as liberdades tomadas pelo juiz administrativo e civil relativamente à filosofia da responsabilidade.

As exigências dos cidadãos (busca de cuidados de qualidade e de uma medicina sem erro) constituem elementos de pressão que conduzem para uma necessária adaptação dos conceitos de responsabilidade. Mas, se para os doentes o direito de reparação de um prejuízo constitui um dos seus direitos fundamentais, não se deve perder de vista que a atividade médica não é uma ciência exata e que as novas tecnologias de ponta, constituindo ao mesmo tempo novas contribuições para um melhor estado de saúde, podem comportar riscos quando de sua utilização.

Vamos ver que se o legislador, por ocasião da lei de 4 de março de 2002 sobre os direitos dos pacientes e a qualidade do sistema de saúde, organizando um novo regime jurídico para as infecções hospitalares, foi conduzido a repor em causa certos aspectos da jurisprudência anterior, nomeadamente sobre a questão da obrigação de segurança do resultado relativa aos médicos, em contrapartida ele retomou para si vários outros aspectos. Antes de ir mais adiante, parece indispensável, para apreciar a natureza e a amplitude das evoluçōes desse novo quadro legal em matéria de responsabilidade no caso de infecção hospitalar e reparação dos prejuízos devidos a tais infecçōes, recordar sumariamente qual era o estado anterior da jurisprudência tanto civil administrativa na matéria.

O exame da evolução do contencioso destes últimos dois anos mostra, incontestavelmente, que a jurisprudência civil e administrativa é bastante favorável para os doentes. Assim, no que se refere ao juiz administrativo, com as jurisprudências Gomez e Bianchi houve uma evolução declarando o hospital responsável sem culpa, primeiro na implementação de uma técnica nova não imposta pela razão proporcional e cujas conseqüências são desconhecidas e, depois, por um risco cuja existência é conhecida, mas de ocorrência excepcional e grave ${ }^{(8)}$. A infecção hospitalar pode, portanto, às vezes, entrar nesse caso.

A fim de favorecer a indenização do doente vítima de infecções hospitalares, adotou-se o princípio da presunção de culpa, pelas duas ordens de órgão jurisdicional. Com efeito, anteriormente, a indenização do doente vítima de tais infecções era subordinada ao regime da responsabilidade por culpa, o que colocava o doente numa posição difícil, dado que devia trazer a prova da culpa, do prejuízo e da relação de causalidade entre a culpa e o prejuízo ${ }^{(9)}$.

(8) C. A. A. Lyon, 21 décembre 1990, Consorts Gomez, Rec. Leb. p. 498, J. C. P., 1991, II, 21698, note J. Moreau ; Gaz. Pal., 1991, p. 440, note D. Chabanol. CE Ass. 9 avril 1993, Bianchi, Rec. Leb. p. 127

(9) V. O arrêt Savelli 18 novembre 1960, Rec. Leb. P. 640, que foi o primeiro Acórdão do Conselho de Estado a se referir a um problema de infecção hospitalar. Nesse caso, uma criança com rubéola foi colocada ao lado de um paciente com varíola. A criança contraiu a varíola e morreu algum tempo depois. Desde esse Acórdão Savelli, o juiz administrativo invoca a presunção de culpa nas seguintes situações: 
O Conselho de Estado, com o acórdão Cohen de 9 de dezembro de $1988^{(10)}$, reteve, pela primeira vez, o regime da presunção de culpa em matéria de infecção hospitalar. Com o objetivo de favorecer a indenização, tomando por nossa a fórmula de um comentador, o órgão jurisdicional administrativo "desmedicalizou" a responsabilidade hospitalar, colocando-a no terreno da organização do serviço. Para o juiz "ainda que nenhuma culpa médica grave em matéria de assepsia possa ser imputada aos médicos que praticaram a intervenção, o simples fato de que uma injeção foi aplicada pode acarretar culpa na organização e no funcionamento do serviço".

Compreende-se facilmente aqui a importância do recurso à presunção de culpa, dado que tem por efeito inverter o ônus da prova impondo ao réu que estabeleça que nenhuma culpa que lhe poderia ser imputável está na origem do dano. No entanto, como recordou o relatório do Conselho de Estado de 1998, se o recurso à presunção de culpa é lógico quando a culpa é impossível de provar, mesmo que manifesta (como foi o caso, por exemplo, da contaminação por varíola de um doente que tinha sido inadvertidamente colocado no quarto de um outro doente suspeito de ser portador dessa doença muito contagiosa $\left.{ }^{(11)}\right)$; em contrapartida, este regime de responsabilidade parece manifestamente duro no que respeita a um estabelecimento hospitalar que tomou todas as medidas sanitárias adequadas, não tendo cometido, por conseguinte, qualquer falta. É necessário, com efeito, não perder de vista que é impossível eliminar todas as fontes potenciais de contaminação no âmbito de um estabelecimento de saúde. Bem freqüentemente os estabelecimentos de saúde estão na impossibilidade de demonstrar a ausência de culpa da sua parte. Essa situação fez o Conselho de Estado dizer que "existe portanto um hiato entre a realidade técnica e o princípio mesmo do regime da responsabilidade por presunção da culpa"(12). Isso explica, sem dúvida, porque em 1999 certas decisões consideraram que mesmo se for demonstrado que nenhuma falta foi cometida, por exemplo, num processo de esterilização, o estabelecimento de saúde pode, contudo, ser condenado a compensar a vítima $^{(13)}$.

quando ele estima que a infecção contraída apareceu sem relação com os motivos da hospitalização, ou quando ela apareceu como conseqüência de uma complicação.

(10) CE. 9 dec. 1988, Rec. Leb. P. 431. A jurisprudência administrativa considerava que essa presunção de culpa era simples e não absoluta, o que significa que o estabelecimento de cuidados pode escapar à sua responsabilidade se provar que tomou todas as precauçōes para evitar uma eventual contaminação. Em 1976, o senhor COHEN submeteu-se a uma sacoradiculografia e ao tratamento de uma hérnia de disco. Ele foi, então, atingido por uma infecção meníngea complicada por uma lesão na espinha dorsal. Finalmente ele sofreu uma paralisia dos membros inferiores, do abdômen e da parte baixa do tronco. $O$ Conselho de Estado estimou que não houve culpa médica grave, especialmente em matéria de assepsia. Entretanto, o fato que ta/infecção tenha podido se manifestar revela uma culpa na organização ou funcionamento do serviço publico hospitalar, a quem incumbe fornecer ao pessoal médico materiais e produtos estéreis.

(11) V. L'arrêt Savelli 18 novembre 1960, op. cit.

(12) EDCE, 1998, p. 247.

(13) V. nesse sentido CE 31 mars 1999, Assistance publique de Marseille, n. 1817019. No caso, se tratava de uma pessoa que havia sido hospitalizada para uma cirurgia. Depois da alta, ela continuou o 
O Tribunal de Cassação, com o acórdão Bonnici de 21 de maio de 1996, reteve a presunção de culpa considerando que "presume-se a clínica responsável por uma infecção contraída por um doente na hora da intervenção praticada em sala de operação, a menos que prove a ausência de culpa da sua parte"(14). Deve-se notar, igualmente, que em 1998 o Tribunal de Cassação, confirmando esta jurisprudência, assimilou uma sala de parto ao bloco operatório(15).

Em matéria de infecçōes hospitalares, o juiz judicial vai operar uma reversão da jurisprudência, por ocasião dos três acórdãos datados de 29 de junho de $1999^{(16)}$, considerando que os estabelecimentos de saúde e os médicos eram responsáveis por uma obrigação de segurança de resultado. O Tribunal declarou, com efeito, "que é esperado que o contrato de hospitalização e de cuidados concluído entre um doente e um estabelecimento de saúde põe a cargo deste último, em matéria de infecção hospitalar, uma obrigação de segurança e de resultado da qual ele não pode liberar-se, se não trazendo a prova de uma causa outra", e que é "esperado que o médico tenha, no que diz respeito ao seu doente, uma obrigação de segurança e de resultado em matéria de infecção hospitalar, da qual apenas se poderá liberar trazendo a prova de uma causa outra". Note-se, igualmente, que o Tribunal de Cassação estendeu essa obrigação às infecções hospitalares em conseqüência de ato médico realizado em consultório médico(17). Assim, a Corte de Cassação agravava, por conseguinte, a responsabilidade dos médicos que, é necessário recordá-lo, anteriormente à tal jurisprudência eram reconhecidos responsáveis apenas quando a vítima trouxesse a prova da culpa. No entanto, o órgão jurisdicional supremo da ordem judicial veio, em seguida, limitar o alcance dos acórdãos de 1999, indicando num acórdão de 27 de março de $2001^{(18)}$ que compete ao doente demonstrar que a infecção que o atingiu apresenta um caráter hospitalar, e neste caso o médico tem uma obrigação de segurança de resultado.

tratamento em domicílio, uma enfermeira Ihe administrando uma série de injeções. Depois de alguns meses se diagnosticou uma hepatite B. Ficou claro, com base nos exames pré-operatórios feitos no hospital antes da cirurgia, que o paciente não estava infectado pelo vírus quando de sua admissão. Por outro lado, ficou igualmente claro que a enfermeira utilizou seringas descartáveis, conseqüentemente, atribuiu-se a contaminação ao hospital. O Conselho de Estado estimou que ela se originou de uma falha na organização e funcionamento do serviço hospitalar

(14) Cf. D., 1997, som., p. 287, obs. Mazeaud.

(15) Cf. Arrêt Clinique Belledone, Bull. civ. I. n. 210, 1997. No caso, depois do parto, uma paciente foi hospitalizada uma segunda vez se queixando de fortes dores abdominais e de febre. Constatou-se que ela foi atingida por uma infecção uterina hospitalar resultante da contaminação por streptococus betahemolíticos do grupo A, que infectavam a regiāo de um membro do pessoal presente no momento do parto. A Corte de Cassação, empregando a jurisprudência Bonnici, precisou que uma sala de parto deveria ser semelhante a uma sala de cirurgia.

(16) Cf. J. C.P., éd. G., 1999, II, n. 10138.

(17) Arrêt du 13 février 2001, V. J. C. P. 2 D. G., 2001, IV, n. 1639.

(18) Cf. Dr. Et patr. 2001, n. 95, p.106, obs. F. Chabas. 
O juiz administrativo, entretanto, não reconhece a obrigação de segurança de resultado em matéria de infecção hospitalar, mesmo que ele admita, há muito tempo, em matéria de higiene, pesar sobre hospital uma "verdadeira obrigação de resultado"(19). A evolução do contencioso destes últimos anos no domínio das infecçōes hospitalares ilustra perfeitamente a inadaptação do nosso direito da responsabilidade. A infecção hospitalar é um fenômeno complexo tanto no plano técnico como jurídico. Seria necessário assumir o fato que as infecções hospitalares não são constantemente sinônimo de culpa ou mesmo de insuficiência. Sua ocorrência pode ser aleatória e imprevisível. Se elas podem ser diretamente determinadas pelos cuidados efetuados, elas podem, igualmente, ser provocadas pelos cuidados necessários para um indivíduo "portador são" e/ou com deficiência de imunidade. Numerosos observadores têm, de resto, chamado a atenção para a necessidade de se refletir sobre outro sistema de reparação, sem passar pela responsabilidade, exceto se uma falha de higiene tiver sido cometida ${ }^{(20)}$. Mas, até agora esta abordagem tinha dificuldade em penetrar em nosso direito positivo, como pôde constatá-lo, especialmente, a professora Geneviève Viney(21). Foi então num contexto de urgência que o legislador se debruçou sobre esse aspecto do problema.

O legislador, com a lei de 4 de março de 2002 sobre os direitos dos pacientes e a qualidade do sistema de saúde, após ter confirmado o caráter culposo da infecção hospitalar, depois erigido o princípio de uma responsabilidade sem culpa para os estabelecimentos de serviços ou organismos nos quais são realizados atos individuais de prevenção, de diagnóstico ou de cuidados no caso desse tipo de infecção, finalmente cruzou o rubicão (cf. do título IV da lei, relativo à reparação das conseqüências dos riscos sanitários), operando a dissociação da responsabilidade dos atores de saúde da indenização das conseqüências prejudiciais do acidente médico, da afecção iatrogênica ou da infecção hospitalar não-culposa e baseada na solidariedade nacional. Esta inovação tem por objetivo encontrar um ponto de equilíbrio entre os interesses da vítima, os profissionais de saúde e os estabelecimentos de saúde.

No âmbito da apresentação dos traços marcantes do novo regime jurídico relativo às infecções hospitalares, buscar-se-á numa primeira parte precisar as implicações no plano contencioso da necessária confirmação do caráter culposo pelo legislador, tendo em conta certos desenvolvimentos jurisprudenciais evocados previamente; em seguida, numa segunda parte interessar-se-á pelo exame do direito à reparação e pela ação de responsa-

(19) V. sobre esse ponto S. Daël, Concl. Sous CE 9 avril 1993, Bianchi, R. F. D. A., 1993, p. 573

(20) cf. CLÉMENT, Cyril. 1990-2002: une période jurisprudentielle faste pour les droits des patients. Revue Générale de Droit Médical, n. 7, p. 31-46, 2002.

(21) V. Em especial VINEY, G. L'avenir des régimes d'indemnisation indépendant de la responsabilité civile. In: Le juge entre deux millénaires. Mélanges Pierre Drai. Paris: Dalloz, 2000. p. 671 et s. 
bilidade no caso de risco hospitalar. No âmbito dessa parte, proceder-se-á naturalmente a uma análise crítica das modificaçōes introduzidas pela lei de 31 de dezembro de 2002 relativa à responsabilidade civil médica em matéria de indenização das infecções hospitalares.

Se no âmbito deste estudo a atenção recai sobre as infecções hospitalares dos doentes, não se deve esquecer, contudo, que esse tipo de infecção vitima também o pessoal dos estabelecimentos de saúde (por exemplo, para o pessoal que trabalha na assistência existe em especial o risco de acidente por exposição ao sangue contaminado ou mesmo viral - HIV, hepatite B e C).

\section{A NECESSÁRIA CONFIRMAÇÃO DO CARÁTER CULPOSO DA INFECÇÃO HOSPITALAR}

A confirmação do princípio da responsabilidade por culpa em matéria de infecções hospitalares no que diz respeito às pessoas físicas profissionais de saúde, dentre elas os médicos, coloca, com um interesse renovado, a questão da necessidade ou não de uma definição legal desse tipo de infecção.

\section{A. A ausência de definição legal da infecção hospitalar}

Ainda que a Lei n. 98-535, de 1 de julho de 1998 relativa à vigilância sanitária e o controle da segurança sanitária dos produtos destinados ao homem tenha consagrado no plano legal o conceito de infecção hospitalar, obrigando os estabelecimentos de saúde, públicos e privados, de acordo com o art. L 6111-1 CSP, a organizar no seu seio "a luta contra as infecçōes hospitalares e outras infecções iatrogênicas" e a instaurar um sistema que permite assegurar a esterilização dos dispositivos médicos, é forçoso constatar que a infecção hospitalar não tem definição legal. A questão da definição da infecção hospitalar foi objeto de discussões por ocasião dos trabaIhos parlamentares que conduziram à adoção da lei de 4 de março de 2002 sobre os direitos dos pacientes e a qualidade do sistema de saúde; mas, ao final o legislador não regulou esse problema de definição; conseqüentemente, compete aos órgãos jurisdicionais precisar o que se entende por infecção hospitalar.

De quais definições dispunha-se até agora? Dispunha-se de definições elaboradas no âmbito europeu e no âmbito nacional. De acordo com o Comitê dos Ministros do Conselho da Europa (25 de outubro de 1984), "chama-se infecção hospitalar qualquer doença contraída no hospital, devido a microorganismos clinicamente e/ou microbiologiquemente reconheciveis, que afetam: seja o paciente, devido à sua admissão ao hospital ou aos cuidados que recebeu como doente hospitalizado ou em tratamento ambu- 
latorial, quer o pessoal hospitalar devido à sua atividade, não importando que os sintomas da doença apareçam ou não ao tempo em que o interessado se encontra no hospital". Em outros termos, a infecção se diz hospitalar se ela não estiver presente na admissão hospitalar (critério aplicável a qualquer infecção: angina, gripe etc. ...). Quando não se consegue estabelecer com precisão a situação de admissão, tradicionalmente se aceita um prazo de pelo menos 48 horas para distinguir entre uma infecção de aquisição comunitária e uma infecção hospitalar (22). No plano nacional, a circular do Ministério da Saúde n. 263, de 13 de outubro de 1988, relativa à organização da vigilância e a prevenção das infecçōes hospitalares traz pela primeira vez uma definição da noção de infecçōes hospitalares. Compreende-se por infecção hospitalar "qualquer doença provocada por microorganismos, contraída num estabelecimento de cuidados, por qualquer doente após a sua admissão, quer para uma hospitalização, quer para receber cuidados ambulatóriais, seja que os sintomas apareçam durante a estada no hospital ou após, seja a infecção reconhecível ou não nos planos clínico e/ou microbiológico". Em seguida, em 1992, a definição foi assim alargada pelo Conselho Superior de Higiene: "são as infecções ausentes quando da admissão hospitalar". Depois, a Circular n. 645, de 29 de dezembro de 2000, revogou a circular de 1988 e as infecções hospitalares foram definidas muito laconicamente como "infecções contraídas num estabelecimento de saúde". Essa circular remete ao documento intitulado "100 recomendações para a vigilância e a prevenção das infecções hospitalares"(23) que precisa, nomeadamente, que se está na presença de uma infecção hospitalar" se ela aparece no curso ou na seqüência de uma hospitalização e se estivesse ausente no momento de internação hospitalar". Este critério é aplicável a qualquer infecção. Quando a situação precisa na admissão não é conhecida, um prazo de 48 horas após a admissão (ou um prazo superior ao período de incubação quando este é conhecido) é aceito geralmente para distinguir uma infecção hospitalar de uma infecção comunitária. No entanto, se recomenda avaliar, em cada caso duvidoso, a plausibilidade da relação causal entre hospitalização e infecção. Para as infecçōes da região operatória, consideravam-se como hospitalares as infecçōes ocorridas nos primeiros 30 dias de acordo com a intervenção, ou, se houve a colocação de uma prótese ou de um implante, no ano que segue à intervenção.

Distinguem-se habitualmente, no âmbito médico, dois grandes tipos de infecções hospitalares, as infecções exógenas e as endógenas ${ }^{(24)}$. No

(22) V. Conselho Superior de Higiene Pública da França " 100 recomendaçōes para a vigilância e a prevenção das infecçōes hospitalares". V. no site do MINISTÈRE DE L'EMPLOI ET DE LA SOLIDARITÉ, Secrétariat d'État à la santé et à l'action sociale, Comité technique national des infections nosocomiales - deuxième édition, 1999. Disponivel em: <http:/hww.sante.gouv.fr/htm/pontsur/hosoco/guide/sommaire.html>.

(23) Id. Ibid.

(24) As infecçōes de origem "exógena" são infecçōes cruzadas, transmitidas de um paciente para o outro pelas mãos ou pelos instrumentos de trabalho do pessoal médico ou paramédico, ou infecções 
âmbito do direito jurisprudencial, até agora o Conselho de Estado e o Tribunal de Cassação sempre tinham se recusado a operar uma distinção entre as infecções endógenas e exógenas e aplicavam o mesmo regime de responsabilidade qualquer que fosse a natureza da infecção. Ora parece que esta postura está em vias de ser abandonada, desde o acórdão de 27 de setembro de 2002 do Conselho de Estado, relativo a um caso de infecção hospitalar ${ }^{(25)}$. Com efeito, na espécie, o órgão jurisdicional supremo da ordem administrativa faz escapar ao regime da presunção de culpa, quase irrefutável, as infecções hospitalares endógenas. O Conselho de Estado considerou "que resulta da instrução que os germes da infecção que se declarou na seqüência da esterilização tubária sofrida pela Sra. N. e que necessitou uma ablação da trompa direita e do seu ovário direito já estavam presentes no organismo da paciente antes da primeira intervenção; que, nessa condição, a interessada não está autorizada a sustentar que a infecção de que ela sofre originou-se de uma falha da organização ou do funcionamento do serviço". Percebe-se, da leitura do acórdão, a importância da distinção estabelecida mesmo se é ainda ligeiramente cedo para apreciar plenamente o alcance de tal jurisprudência. O que quer que seja, parece que o órgão jurisdicional administrativo escolheu adotar uma definição da infecção hospitalar, que foi a da Academia de Medicina, a saber, uma infecção contraída devido à atividade de cuidados, excluindo as infecções endógenas, que são, por seu lado, inerentes ao risco terapêutico ${ }^{(26)}$.

\section{B. As infecçóes hospitalares e a restauração do princípio da responsabilidade por culpa}

Nos termos do art. L. 1142-1 I do CSP "fora do caso onde a sua responsabilidade é incorrida devido a um defeito de um produto de saúde, os profissionais da saúde mencionados na quarta parte do presente código, bem como qualquer estabelecimento, serviços ou organismos nos quais são realizados atos individuais de prevençāo, de diagnóstico ou cuidados são responsáveis das conseqüências prejudiciais de atos de prevenção, de diagnóstico ou de cuidados apenas no caso de culpa". Os estabelecimentos, serviços e organismos supracitados são responsáveis pelos prejuízos que resultam de infecções hospitalares, exceto se trazem a prova de uma causa outra". Assim, neste artigo, se deixa subsistir dois casos de responsabilidade

provocadas pelos germes trazidos pelo pessoal ou os visitantes, ou infecções ligadas à contaminação do ambiente hospitalar (água, ar, materiais, alimentação). Existe infecção de origem "endógena" quando o doente se infecta com seus próprios germes, em conseqüência de um ato invasivo ou em razão de uma fragilidade particular.

(25) CE 27 septembre 2002 "Mme Martine N. n. 2111370".

(26) Cf. FLAVIN, Patrick. Infections nosocomiales, arrêt du 27 septembre 2002. Commentaire d'arrêt. Disponivel em: <http://www.sham.fr/actus/Inf_nos.htm>. 
sem culpa, notadamente, na hipótese de infecções hospitalares quando são exclusivamente imputáveis aos estabelecimentos e serviço de saúde excluindo os médicos, restaura, sobretudo, o princípio da responsabilidade por culpa, no seu primeiro parágrafo.

Essa disposição aparece como uma reação legislativa a alguns dos desenvolvimentos jurisprudenciais contestáveis, em especial aos que se referem à questão da responsabilidade em matéria de infecções hospitalares. Com efeito, no âmbito da jurisprudência administrativa e, mais particularmente, da jurisprudência Bianchi, para ser compensado no âmbito do risco, o dano deve ser de uma gravidade suficiente, ora não se deve esquecer que a maior parte das infecçōes hospitalares não causa prejuízos que não apresentam tal caráter. Quanto ao olhar da jurisprudência judicial, os danos devidos a infecções hospitalares não deveriam ser logicamente reparados devido à exclusão de reparação do risco terapêutico. A lei de 4 de março de 2002 veio clarear as coisas, afastando a qualificação de risco médico e afirmando expressamente o caráter culposo da infecção hospitalar, o que favorece, portanto, a indenização das pessoas atingidas por uma infecção hospitalar.

\section{Para esclarecer: a qualificação do ato culposo para a infecção} hospitalar

Esse artigo permite esclarecer uma situação no plano jurídico, pondo fim a uma situação paradoxal no âmbito do contencioso judiciário. Com efeito, os julgados da Corte de Cassação excluíram muito claramente toda possibilidade de reparação do risco terapêutico (sendo a obrigação de assistência uma obrigação de meio, todo ato médico comporta por definição uma dimensão de risco irredutível). Mas, ao mesmo tempo, a jurisdição judiciária, com os julgados ditos dos staphylococcus aureus de 29 de junho de 1999, fez pesar sobre os médicos, em matéria de infecção hospitalar, uma obrigação de segurança de resultado. Ora, não se pode ver nessa jurisprudência, em certa medida, o reconhecimento implícito da indenização do risco médico, se se considera que o risco terapêutico recobre a infecção hospitalar. Apenas a intervenção do legislador poderia permitir a saída dessa situação incoerente.

O art. L. 1142-1 vem se contrapor à jurisprudência civil em matéria de infecções hospitalares, que considerava que os estabelecimentos de saúde e os médicos estavam obrigados à segurança de resultado. O Tribunal de Cassação tinha mesmo, num acórdão de 13 de fevereiro de 2001, estendido essa obrigação às infecções que se seguiam a um ato médico realizado no consultório. Com efeito, fazendo nosso o argumento de Pierre Sargos, presidente do Tribunal de Cassação, parece difícil, até mesmo artificial, "assimilar 
o consultório médico a um estabelecimento, serviço ou organismo visado pelo art. L. 1142-1 do CSP, com a reserva, se for o caso, de consultórios de grupo com salas específicas onde são realizados atos invasivos susceptíveis de provocar uma infecção hospitalar".

Por último, o art. L. 1142-1 do CSP parece rejeitar a transposição ao médico da jurisprudência Bonnici, de 21 de maio de 1996, que aceitou a presunção de culpa em matéria de infecção hospitalar considerando "que a clínica é presumida responsável de uma infecção contraída por um doente na hora de uma intervenção praticada em sala de operação a menos que se prove a ausência de culpa de sua parte", ou seja, que ela não falhou na implementação de medidas de assepsia.

\section{L.1142-1 ou o regresso anunciado da culpa provada para identificar a responsabilidade do médico}

Logicamente 0 art. L. 1142-1 deve ser interpretado como anunciando o regresso da responsabilidade fundada na culpa provada para identificar a responsabilidade de médicos no caso de infecção consecutiva a um ato invasivo, como uma injeção aplicada em seu doente. Isso significa que se retornará ao estado da jurisprudência anterior a 1996, período em que o médico, para retomar a fórmula da célebre jurisprudência Mercier de 1936, deveria dispensar a seu doente um cuidado conforme "conhecimentos adquiridos pela ciência". Em conseqüência, a obrigação de respeito dos princípios e regras de assepsia e de profilaxia de ponta, tanto no âmbito hospitalar como ambulatorial, aparece como "a regra de base constante da ciência médica" para retomar uma expressão consagrada na matéria.

\section{SEPARAÇÃO DO DIREITO À REPARAÇÃO DA AÇÃO DE RESPONSABILIDADE NO CASO DE RISCO HOSPITALAR}

O legislador introduziu, com o objetivo de favorecer a situação dos doentes, duas inovações importantes em matéria de infecção hospitalar: de uma parte, a afirmação do princípio da responsabilidade sem culpa dos estabelecimentos de saúde e de outra, a entrada das infecções hospitalares no quadro geral do risco terapêutico e da implementação de um procedimento de indenização. Estas inovações no regime jurídico das infecções hospitalares, incluindo as modificações introduzidas pela lei de 31 de dezembro de 2002, relativa à responsabilidade civil médica, adotada para evitar uma situação de bloqueio do sistema de cuidados em seguida às pressōes dos seguradores, provocam várias observaçōes. 


\section{A. A responsabilidade sem culpa dos estabelecimentos e serviços de saúde}

Se a lei de 4 de março veio se contrapor a certos aspectos contestáveis da jurisprudência anterior relativa aos médicos, como se acaba de demonstrar, ao mesmo tempo esse texto integrou em grande parte as lógicas desenvolvidas em matéria de infecções hospitalares pela jurisprudência do Conselho de Estado no que diz respeito aos hospitais públicos (cf. acórdão Cohen) e a do Tribunal de Cassação (acórdãos Staphylococcus aureus), no que se refere aos estabelecimentos privados. Como sublinham os relatórios parlamentares, a lei consagrou, nomeadamente, a jurisprudência do Tribunal de Cassação, art. L 1142-1 alínea I, afirmando que "os estabelecimentos, serviços e organismos supracitados são responsáveis pelos danos que resultam de infecções hospitalares, exceto se fizerem prova de causa outra". Deve-se notar, igualmente, a título de precisão complementar, que o regime da obrigação de resultado pesa sobre os médicos e os estabelecimentos de saúde no que se refere aos danos decorrentes do emprego de um produto de saúde.

\section{B. A entrada das infecções hospitalares no âmbito geral do risco terapêutico}

Com a lei de 4 de março de 2002 se assiste ao reconhecimento do risco pelo acaso sem culpa para as infecções hospitalares (como de resto para os acidentes médicos e as afeiçōes iatrogênicas). Certos autores já utilizam, a exemplo de Pierre Sargos, a expressão risco hospitalar ${ }^{(27)}$. Diz o art. L. 1142-1 2 "quando a responsabilidade de um profissional, um estabelecimento, de serviço ou organismo mencionada no l ou de um produtor de produtos não for promovida, um acidente médico, uma afecção iatrogênica ou uma infecção hospitalar dá direito à reparação dos danos do doente ao abrigo da solidariedade nacional, quando forem diretamente imputáveis a atos de prevenção, de diagnóstico ou de cuidados que tenham tido para o paciente conseqüências anormais em relação ao seu atual estado de saúde ou à sua evolução previsível, e apresentarem um caráter de gravidade, fixado por decreto, apreciado em relação à perda de capacidades funcionais e as conseqüências sobre a vida privada e profissional, medidas tomando em conta, especialmente, a taxa de incapacidade permanente ou a duração da incapacidade temporária de trabalho". "Dá direito à reparação do dano a título de solidariedade nacional uma taxa de incapacidade permanente superior a um percentual de um limite específico fixado por decreto: essa percentagem, ao máximo igual a $25 \%$ é determinada por decreto".

(27) V. SARGOS, P. Le nouveau régime juridique des infections nosocomiales. Loi n. 2002-303 du 4 mars 2002. JCP. la semaine juridique, édition général, n. 25, p. 1119, juin. 2002. 
Uma primeira observação se impõe no que diz respeito à noção de risco terapêutico e a relação que ele possa ter com as infecçōes hospitalares. Deve-se destacar, certa ambigüidade. $\mathrm{Na}$ lei, as expressões risco terapêutico e acidente médico não culposo não estão presentes, tendo o legislador preferido operar uma distinção entre três espécies: o acidente médico, a afecção iatrogênica e as infecções hospitalares. Contudo, mesmo que a lei não utilize o termo risco terapêutico, o legislador finalmente deu uma definição do risco terapêutico, par default. Definiu-o de maneira implícita, na medida em que o risco abrange o acidente médico não culposo, a afecção iatrogênica sem culpa e a causa estranha exoneradora para os produtos defeituosos ou as infecções hospitalares. Por outras palavras, a lei parece integrar na definição do risco terapêutico a infecção hospitalar no caso de o profissional de saúde se beneficiar de uma causa estranha exoneradora. Mas, como acertadamente precisou Nadège Reboul-Maupin, "na realidade ela está a meio caminho entre o risco terapêutico puro e uma forma de erro médico". "Para tanto, ela se introduzirá novamente na definição do risco quando a causa estranha for imprevisível, suscitada por ela. E é por isso que ela parece fazer parte do risco terapêutico". Quando o acidente médico prejudicial não preenche as condições da responsabilidade médica, integra-se no domínio do risco.

A segunda observação se refere às condições limitativas que devem ser reunidas para se beneficiar da solidariedade nacional. $O$ enunciado das três condiçōes (1. imputabilidade direta do dano a atos de prevenção, de diagnóstico ou de cuidados; 2 . atos que tenham tido conseqüências anormais para os doentes; 3. apresentar certo caráter de gravidade fixado por decreto), faz lembrar as condições afirmadas pelo juiz administrativo no acórdão Bianchi, de 9 de abril de 1993. Para que o risco terapêutico seja indenizável, - Conselho de Estado indicou sete condiçōes cumulativas para se beneficiar de regime de responsabilidade sem culpa: 1) o ato médico deve ser necessário; 2) nenhuma contra-indicação ao tratamento deve existir; 3) o risco deve ser conhecido; 4) ele deve ser excepcional; 5) uma relação direta entre o ato e o prejuízo deve existir; 6) o dano não deve ter nenhuma relação com o estado previsível na ausência de terapêutica; 7) o dano deve apresentar um caráter de extrema gravidade.

Vê-se que, se o juiz administrativo admitiu a indenização do risco terapêutico, as condições que abrem o acesso a esse direito foram muito severas. É forçoso constatar que o legislador, com a lei de 4 de março de 2002, não retomou o conjunto dessas condições e demonstrou maior flexibilidade. Com efeito, o legislador, sem operar a distinção entre os estabelecimentos hospitalares públicos e os estabelecimentos do setor privado, indicando os atos que não escapam do imprevisível, do risco, mesmo se forem realizados perfeitamente, se apóia na anormalidade das conseqüências e precisa a gravidade prevista indicando um limiar, exigência que não se reencontrava na jurisprudência Bianchi. 


\section{O procedimento de indenização da infecção hospitalar}

Este procedimento se apóia em duas criações institucionais. Por um lado, no plano regional, a comissão de conciliação e indenização dos acidentes médicos, das afecções iatrogênicas e de infecçōes hospitalares que tem por tarefa favorecer a solução amigável dos litígios relativos aos acidentes médicos, às afecções iatrogênicas e às infecções hospitalares ${ }^{(28)} e$, por outro lado, no plano nacional, o serviço nacional de indenização dos acidentes médicos, das afecções iatrogênicas e infecções hospitalares (ONIAM) que vai intervir em complemento à comissão regional de conciliação(29).

Em primeiro lugar, o legislador põe ao serviço da vítima uma via extrajurisdicional para reparar os prejuízos sofridos: as comissões regionais de conciliação e indenização dos acidentes médicos, das afecções iatrogênicas e de infecções hospitalares que aparecem como "o balcão único" de reparação(30). A comissão regional de conciliação, se o dano apresenta o caráter de gravidade necessário, formula um parecer sobre as causas, a natureza e a amplitude dos danos, bem como sobre o regime de indenização aplicável. Esse parecer vai permitir o pagamento da indenização, quer através da solidariedade nacional, quer através do segurador. É importante acrescentar que a vítima tem a possibilidade de provocar o órgão jurisdicional competente. Em outros termos, o procedimento dessas comissóes é facultativo. No caso de a vítima optar por se dirigir ao juiz competente, este pode, se considerar que os danos sofridos não implicam a responsabilidade de um profissional ou um estabelecimento de saúde, chamar à lide o Serviço Nacional de Indenização dos Acidentes Médicos, das Afecçōes latrogênicas e de Infecções Hospitalares (ONIAM), que se torna réu no processo (arts. L 114221). Em todos os casos, a vítima "informa, respectivamente, a Comissão, dos procedimentos jurisdicionais em curso, e o juiz, da execução na Comissão Regional" (arts. L. 1142-7).

Se a Comissão considera que o dano pode implicar a responsabilidade do profissional de saúde (médico, estabelecimento de saúde, serviços de saúde, ou produtor de um produto de interesse para a saúde), o segurador, fiador da responsabilidade do profissional de saúde, dirige ao paciente-vítima uma oferta de indenização que deve assegurar a reparação integral do prejuízo. Tal oferta apresenta caráter provisório e se torna definitiva

(28) Em cada regiáo, nos termos do artigo L $1142-5$ do C. S. P. " uma comissáo regional de conciliação $\theta$ de indenizaçáo é encarregada de facilitar a resoluçáo amigável dos litígios relativos aos acidentes médicos, às afecçöes iatrogênicas $\theta$ às infecçöes hospitalares".

(29) O Serviço Nacional de Indenização dos Acidentes Médicos, das Afecções latrogênicas (ou seja, provocadas pelo tratamento) e de Infecçóes Hospitalares (contraídas durante a execução de um ato médico) - ONI - foi instalado em 14 de outubro de 2002, pelo Ministro da Saúde, Jean-François Mattéi. O ONI, competente para indenizar todos os pacientes vítimas de acidentes médicos não-culposos, é atualmente presidido pelo ex-senador Claude Huriet.

(30) ESPER, C. op. cit., p. 56. 
num prazo de um mês a partir da data em que o segurador é informado da liquidação do estado da vítima. Em conformidade com o art. 2.044 do Código Civil, a aceitação da oferta equivale à transação. Quanto ao ONIAM, ele substitui-se ao segurador, quer no caso de recusa tácita (silêncio) ou expressa do segurador de fazer uma oferta, quer no caso de ausência de seguro do responsável pelo dano. Nesses casos, o procedimento é o mesmo que aqueles instituídos frente à Comissão Regional.

Criando o ONIAM(31), para o procedimento de indenização (cujo financiamento é assegurado, essencialmente, por uma dotação global prevista na lei de financiamento da seguridade social), o legislador quis, com efeito, pôr termo às injustiças causadas às vítimas em matéria de reparação dos danos sofridos quando da ocorrência de um risco terapêutico. Assim, se pretendeu substituir um procedimento judicial longo e dispendioso por um procedimento mais rápido e "desjudiciarizado" de indenização(32): se um risco terapêutico é constatado, uma oferta de indenização é feita pelo Serviço Nacional de Indenização.

\section{As turbulências causadas pela lei de 4 de março de 2002 e as modificaçôes introduzidas pela Lei n. 2002-1577, de 30 de dezembro de 2002, relativa à responsabilidade civil referente ao regime de indenização das infecçōes hospitalares}

A adoção da lei de 4 de março de 2002 suscitou vivas polêmicas, particularmente em razão das posiçōes tomadas por certos seguradores e da agitação dos médicos, largamente retransmitida pela imprensa, que viu os seus prêmios de seguros consideravelmente aumentados. Resumidamente, perante um risco anunciado de paralisia do sistema de saúde pela impossibilidade de os profissionais e os estabelecimentos de saúde se assegurarem contra os riscos inevitáveis que sua atividade comporta, era imperativamente necessário reagir o mais rapidamente possível para garantir a continuidade da cobertura assecuratória do setor saúde, pelo menos por um tempo, e garantir, portanto, a continuação da atividade médica em $1^{\circ}$ de janeiro de 2003. Parecendo que o mercado de seguro de responsabilidade

(31) O ONI tem o estatuto jurídico de estabelecimento público administrativo do Estado. Ele está sob a tutela do Ministro da Saúde e é financiado por uma dotação da Seguridade Social e pelo produto do reembolso das despesas de perícia, multas e recursos sub-rogatórios. Dispōe de um conselho de administração cuja composição é fixada por decreto: metade de representantes do Estado, metade de personalidades qualificadas, representantes dos usuários, profissionais e estabelecimentos de saúde, organismos de seguro-saúde, pessoal do serviço. O presidente é nomeado por decreto, assim como o diretor.

(32) RÉFORME du droit de la responsabilité et indemnisation de l'aléa thérapeutique, Dictionnaire permanent bioéthique et biotechnologies. Bulletinn. 113, p. 2282, avr. 2002. V. também REBOUL-MAUPIN, Nadège. L'indemnisation de l'aléa thérapeutique. Petites affiches, n. 122, p. 79, juin 2002. 
civil encontrava-se verdadeiramente sinistrado, várias companhias de seguro não-cooperativas decidiram dele retirar-se. Essa crise foi a origem da proposta de lei relativa à responsabilidade civil, apresentada por Nicolas About para fazer face à tal situação de urgência, que conduziu à adoção da Lei n. 2002-1577, de 30 de dezembro de 2002. Esse texto visa, com efeito, incitar os seguradores a retornar ao mercado da saúde e, nomeadamente, a responsabilidade civil médica. Ele se articula, principalmente, ao redor de dois eixos: por um lado, uma divisão da indenização das infecções hospitalares entre os seguradores e o ONIAM e, por outro lado, um novo regime jurídico para os contratos de seguros de responsabilidade civil médica. Obviamente, neste artigo, vamos nos deter apenas sobre o primeiro aspecto.

Doravante as infecções hospitalares que têm conseqüências financeiras muito pesadas ${ }^{(33)}$, com uma taxa de incapacidade superior a $25 \%$ ou no caso de mortes, deixarão de ser compensáveis pelas companhias de seguro, mas o serão pela solidariedade nacional através do ONIAM, mesmo quando essas infecções são culposas. Deve-se observar que o mesmo regime está previsto para todos os danos (independentemente da taxa de incapacidade) que resultam de uma intervenção médica realizada por profissional ou estabelecimento de saúde fora de sua especialidade, em caso de circunstâncias excepcionais. O objetivo é tranqüilizar os profissionais de saúde que devem socorrer ou levar assistência a uma pessoa em perigo, sem que corram o risco de ser, em seguida, processados por responsabilidade se, infelizmente, algum dano resultar da intervenção realizada fora do quadro habitual da especialidade daquele profissional de saúde. Esses novos casos de indenização pela solidariedade nacional são codificados no art. L. 1142-1-1 do Código da Saúde Pública. Eles são completados pela consideração do agravamento do estado da vítima de uma infecção hospitalar (arts. L. 114717-1), cuja taxa de incapacidade permanente, inicialmente fixada em menos de $25 \%$, termina por exceder tal percentagem, ou pela morte. Neste caso, o ONIAM se substitui ao segurador do estabelecimento de saúde para compensar a vítima, e reembolsa ao segurador as indenizações já vertidas, quando for o caso $^{(34)}$.

Deve-se acrescentar, contudo, que o legislador tomou a sábia precaução, para não desresponsabilizar os estabelecimentos de saúde em matéria de luta contra a ocorrência de infecçōes hospitalares, de manter em proveito do ONIAM a possibilidade de se voltar contra o segurado (ação regressiva)

(33) Essas situações representariam menos de $5 \%$ dos caso, segundo trabalhos parlamentares $V$. Assemblée Nationale, rapport n. 464 présenté par J-P Door, 16 décembre 2002, p. 4.

(34) Com respeito às disposiçōes do novo artigo L. 1142-17-1, J-P Door se interrogava no relatório apresentado à Assembléia Nacional sobre o caráter "retroativo" dessa disposição, que prevê o reembolso pelo ONIAM das somas já versadas pelos seguradores, quando elas correspondiam a uma taxa inferior a $25 \%$, V. A. N. Rapport n. 464, op. cit., p. 11. 
quando for caracterizada a culpa, ou seja, quando for caracterizado o descumprimento das obrigações fixadas pela regulamentação em matéria de luta contra as infecções hospitalares. É necessário lembrar aqui, que o princípio da luta contra as infecções hospitalares, que figura no art. L. 6111-1 do Código de Saúde Pública, se traduz em especial na obrigação de o estabelecimento de saúde definir um programa anual de ação; de constituir em seu seio uma Comissão de Luta contra a Infecção Hospitalar - CLIN; de se dotar de uma equipe operacional de higiene; e de seguir as recomendações das boas práticas. Acrescente-se, igualmente, que para garantir a eficácia da luta contra esse tipo de infecção, os arts. L. 1142-8 alterado e L. 1142-21 prevêem que as comissões regionais de indenização dos acidentes médicos, afecções iatrogênicas e infecções hospitalares (CRCl) devem informar o diretor da agência regional da hospitalização (ARH) competente e o ONI$A M$ das infecções hospitalares de que têm conhecimento e que apresentam o caráter de gravidade previamente evocado. O diretor da ARH poderá, eventualmente, tomar as decisões que se imporão em função da qualidade sanitária desse estabelecimento (suspensão, encerramento).

Se este texto é freqüentemente apresentado como um compromisso constituído na urgência, buscando ter em conta os interesses dos pacientes, das profissões de saúde, ele aparece, de fato, como uma concessão importante ao mundo do seguro, em conseqüência do que se pode qualificar, correndo o risco de ser polêmico, de uma verdadeira chantagem dos seguradores. Como pôde alertar Claude Evin, por ocasião dos debates, as companhias de seguro tentaram fazer crer que sua decisão de se retirar do setor médico era conseqüência direta da aplicação de lei de 4 de março de 2002. Em realidade, a decisão dos seguradores já estava em gestação antes da adoção da lei, que trouxe diversas respostas às suas demandas, permitindoIhes, em especial, ter assento nas comissões regionais encarregadas de apreciar os sinistros. Além disso, Claude Evin recordou, a justo título, que não era exato afirmar que a lei de 4 de março de 2002 criara novos riscos a serem cobertos pelos seguros, porque ela apenas confirmou uma jurisprudência que já se tornara constante.

É claro, considerando as condições de adoção da lei de 31 de dezembro de 2002 (que apenas freou os mais apressados), que já é tempo de, finalmente, empreender uma verdadeira reflexão global sobre a responsabilidade civil médica, para definir precisamente a noção de risco médico e o papel que deve desempenhar o Estado no sistema de indenização das vítimas. A título de precisão, deve-se acrescentar que, no que concerne à aplicação da lei no tempo, o texto de dezembro de 2002 também alterou a lei de 4 de março de 2002, indicando que a Comissão Regional poderá ser provocada apenas em casos de acidentes médicos consecutivos à atividade de prevenção, de diagnóstico ou de cuidados realizados "a contar do dia 5 de setembro de 2001, ainda que tais acidentes médicos, afecções iatrogênicas 
e infecçōes hospitalares sejam objeto de um processo em curso, a menos que exista decisão judicial invocável"(35).

\section{CONCLUSÃO}

Em resumo, nos termos da lei de 4 de março de 2002, antes das modificações da lei de 31 de dezembro de 2002, poder-se-ia, na prática, distinguir dois casos típicos em matéria de infecção hospitalar: 1) em caso de acusação de um estabelecimento, um serviço ou organização onde se realizem atos individuais de prevenção, diagnóstico ou assistência, o estabelecimento é automaticamente responsável, exceto quando faz prova de uma causa outra. Se uma causa outra for provada, cai-se no terreno do risco e a compensação para os danos intervirá dentro da estrutura da solidariedade nacional; 2) em caso de acusação por infecção hospitalar de uma pessoa física profissional de saúde (particularmente o médico), será necessário que a vítima prove a culpa para implicar a responsabilidade do profissional. Se a prova não for feita, ele entra na estrutura do risco e a reparação poderá intervir a título de solidariedade nacional(36).

O sistema da responsabilidade por infecção hospitalar parece a priori interessante, a não ser pelo fato que, para ser indenizado em nome da solidariedade nacional, o risco, e particularmente o risco terapêutico, deve apresentar um determinado grau de gravidade fixado pelo decreto, que "deve ser apreciado com relação à perda da capacidade funcional e às conseqüências para a vida privada e profissional, medidas tendo em conta, especialmente, a taxa de incapacidade permanente ou a duração da incapacidade provisória para o trabalho", devendo ser a taxa de incapacidade igual ou maior que $25 \%$. Entretanto, deve-se considerar que a fixaçăo do ponto inicial em $25 \%$ exclui a maior parte das infecçōes hospitalares ${ }^{(37)}$. Pierre Sargos lem-

(35) Article 3 de la Loi n. 2002-1577 du 30 décembre 2002 (J.O 31 déc.2002, p. 22100). Essa disposição parece particularmente interessante na medida em que ela faz desaparecer uma ambigüidade da lei de 4 de março de 2002, em seu art. 101, que alguém poderia interpretar como aplicável a todos os procedimentos em curso no momento da publicação da lei, mesmo se a data do fato gerador fosse anterior a 5 de setembro de 2001 (nesse sentido V. l'avis de la Cour de Cassation n. 002006P du 22 novembre 2002). Certos problemas continuam, contudo, a se apresentar, como, por exemplo, o que acontecerá quando a manifestação do dano e sua consolidação ocorrerão no futuro.

(36) Entretanto, na prática, pode-se encontrar situaçōes complexas onde serão postos em causa simultaneamente pessoas físicas e estabelecimentos de saúde. Nessas situaçōes, será necessário fazer uma aplicaçāo distributiva. Mas, não se pode esquecer, como sublinha Pierre Sargos, "que em direito, uma condenação in solidum poderá recair sobre um médico por uma açāo culposa que tenha cometido e sobre um estabelecimento de saúde a título de descumprimento de uma obrigação de segurança de resultado, salvo se em seguida for estabelecida, no relacionamento entre eles, uma divisão de responsabilidade" V.SARGOS, P. op. cit., p. 1117.

(37) Quando a vítima de uma infecção hospitalar sofre um dano cuja gravidade é inferior ao limite fixado pelo decreto, o segurador do médico ou do estabelecimento será seu único interlocutor. Se eles chegam a um acordo sobre o princípio da responsabilidade e o montante da reparação, uma transação amigável poderá 
bra, a justo título, que em certos casos, como por exemplo as infecções articulares, as vítimas terão que se submeter a anos de tratamento e às vezes a diversas operações cirúrgicas ${ }^{(38)}$.

Desde a lei de 31 de dezembro de 2002, relativa à responsabilidade civil médica, convém fazer uma distinção entre as infecções hospitalares geradoras de danos graves, que são compensados pelo ONIAM a título de solidariedade nacional, e as infecções hospitalares geradoras de danos leves, que são cobertos pelos seguradores dos profissionais e dos estabelecimentos da saúde, cujo regime de indenização não foi modificado.

\section{REFERENCIAS}

CLÉMENT, Cyril. 1990-2002: une période jurisprudentielle faste pour les droits des patients. Revue Générale de Droit Médical, n. 7, p. 31-46, 2002.

DUNETON, $P$. et al. Organisation et structures de lutte contre les infections nosocomiales en 1995. Médecine et Droit, n. 11, p. 2-23, 1995.

ESPER, C. Les nouvelles instances de réparation des risques sanitaires. Actualités Juri Santé, n. 34, p. 56-58, déc. 2001/janv.2002.

FLAVIN, Patrick. Infections nosocomiales, arrêt du 27 septembre 2002. Commentaire d'arrêt. Disponível em: <http://www.sham.fr/actus/Inf_nos.htm>.

MINISTÈRE DE L'EMPLOI ET DE LA SOLIDARITÉ, Secrétariat d' État à la santé et à l'action sociale, Comité technique national des infections nosocomiales - deuxième édition, 1999. Disponível em: <http://www.sante.gouv.fr/ $\mathrm{htm} /$ pontsur/nosoco/guide/sommaire.html>.

RAYSSAC, R. Le sort des infections nosocomiales. Actualités Juri Santé, 34, p. 50-52, déc. 2001/janv.2002.

REBOUL-MAUPIN, Nadège. L'indemnisation de l'aléa thérapeutique. Petites affiches, n. 122, p. 77-86, juin 2002.

RÉFORME du droit de la responsabilité et indemnisation de l'aléa thérapeutique, Dictionnaire permanent bioéthique et biotechnologies. Bulletin n. 113, avr. 2002.

SARGOS, P. Le nouveau régime juridique des infections nosocomiales. Loi n. 2002-303 du 4 mars 2002. JCP: la semaine juridique, edition général, $n$. 25, p. 1117-1120, juin.2002.

VINEY, G. L'avenir des régimes d'indemnisation indépendant de la responsabilité civile. In: Le juge entre deux millénaires. Mélanges Pierre Drai. Paris: Dalloz, 2000.

se realizar. Na falta de acordo, a vítima deve se dirigir ao juiz competente. Aqui se deve considerar, também, o papel que poderão jogar as comissōes regionais de conciliação, atuando enquanto conciliadores.

(38) SARGOS, P. op. cit., p. 1120. 